Open Access

\title{
Three Cases of Non-Surgical Treatment of Stent Loss During Percutaneous Coronary Intervention
}

\author{
Byung-Ju Shim, MD, Jong-Min Lee, MD, Seung-Jae Lee, MD, Sung Sik Kim, MD, \\ Dong-Hyeon Lee, MD, Woo-Seung Shin, MD, Ji-Han Yu, MD and Sang Hyun Gil, MD \\ Division of Cardiology, Department of Internal Medicine, College of Medicine, The Catholic University of Korea, Seoul, Korea
}

\begin{abstract}
Percutaneous coronary intervention with stenting is widely used for ischemic heart disease. Because stent loss, which occurs rarely during the procedure, might have dire consequences, such as bleeding, stent embolism, acute myocardial infarction, emergency coronary artery bypass graft, and death, appropriate treatment is needed as soon as stent loss occurs. We report three cases of stent loss which were successfully treated with three different non-surgical methods. (Korean Circ J 2010;40:530-535)
\end{abstract}

KEY WORDS: Percutaneous transluminal augoplasty; Stents.

\section{Introduction}

Since the introduction of balloon dilatation of coronary artery lesions, interventional treatment has evolved thanks to numerous advances in procedures, equipment, devices, and indications. Specifically, with the technical advances in stent implantation, the incidence of complications, such as acute coronary occlusion or re-stenosis has been reduced, which has led to a sharp increase in the frequency of stent use. ${ }^{1)}$ During the stenting procedure, however, there may be deviceassociated complications, including balloon rupture, detachment or perforation of a balloon catheter or guide wire, and stent loss. ${ }^{2) 3)}$

Of the device-associated complications mentioned, the incidence of stent loss has diminished with advances in techniques and equipment; however, still stent loss occurs rarely and can also lead to bleeding, stent embolism, acute myocardial infarction, emergency coronary artery bypass graft, and death. Appropriate treatments are therefore needed as soon

Received: January 4, 2010

Accepted: March 5, 2010

Correspondence: Jong-Min Lee, MD, Division of Cardiology, Department of Internal Medicine, College of Medicine, The Catholic University of Korea, 65-1 Geumo-dong, Uijeongbu 480-821, Korea

Tel: 82-31-820-3030, Fax: 82-31-847-0461

E-mail: leejongm@catholic.ac.kr

$@$ This is an Open Access article distributed under the terms of the Creative Commons Attribution Non-Commercial License (http://creativecommons.org/licenses/by-nc/3.0) which permits unrestricted non-commercial use, distribution, and reproduction in any medium, provided the original work is properly cited. as stent loss occurs. ${ }^{4)}$

Although the most desirable treatment is to remove the stent, this is not always feasible. In some cases, the lost stent can be transplanted to the same location and compressed with other stents. We report three cases of stent loss which occurred during percutaneous coronary intervention and were successfully treated with three different non-surgical methods. We also provide a literature review on stent loss.

\section{Cases}

\section{Case 1}

A 64-year-old man was hospitalized due to frequent chest pain, despite oral medication. He had a longstanding history of hypertension. An electrocardiogram (EKG) on admission showed atrial fibrillation and $\mathrm{Q}$ waves in leads II, III, $\mathrm{aV}_{\mathrm{F}}$, and $\mathrm{V}_{2-4}$. On chest $\mathrm{X}$-ray, there were findings suggestive of cardiomegaly. An echocardiography revealed a severe degree of inferior and posterior wall hypokinesis, left and right ventricular dilatation, and a decreased left ventricular ejection fraction of $30 \%$. Coronary angiography performed via the right femoral artery showed $97 \%$ stenosis and calcifications from the proximal to mid-right coronary artery (RCA), 99\% stenosis and calcifications in the proximal left circumflex (LCX) artery, and complete obstruction of the left anterior descending (LAD) artery (Fig. 1A). Percutaneous coronary artery intervention was performed. For the RCA lesion, a 6-Fr Judkins right type 4 (Medtronic, Danvers, MA, USA) guide catheter was used to advance the guide wire into the lesion, a 2.0/15 mm Ryu- 

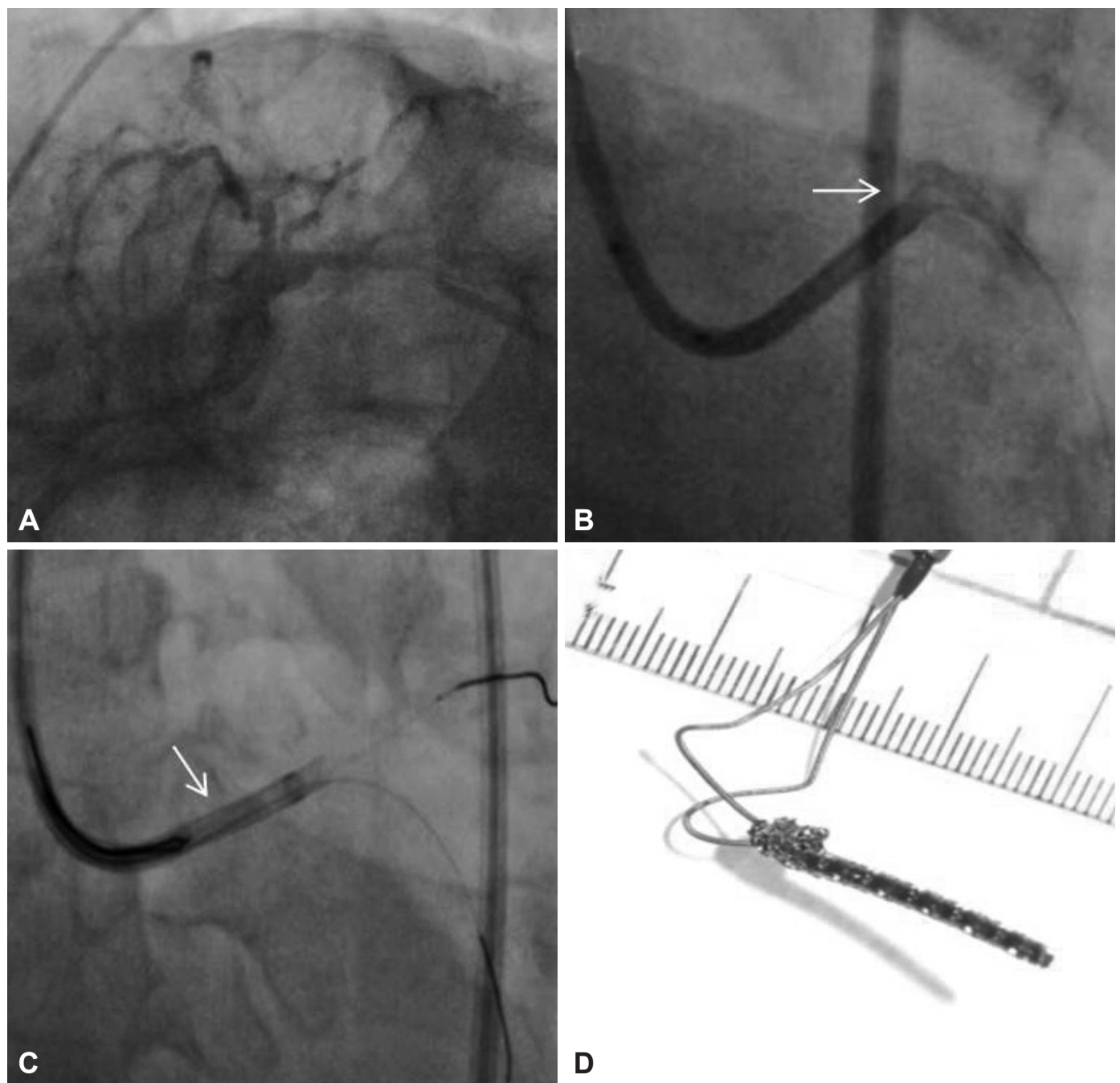

Fig. 1. Case 1. A: left coronary angiography showed chronic total occlusion of the proximal left anterior descending artery (LAD) and severe, calcified stenosis of the proximal left circumflex artery. B: the lost stent $\left\{\right.$ Taxus $^{\mathrm{TM}} 3.0 / 20 \mathrm{~mm}$ (arrow)\} is seen in the proximal LAD. C: the snare (arrow) was tightened around the stent. D: photography of the removed Taxus ${ }^{\mathrm{TM}}$ stent and snare.

jin $^{\mathrm{TM}}$ balloon (Terumo Corporation, Fujinomiya, Japan) was expanded up to a pressure of 6 atm, and because of a residual stenosis of $80-90 \%$, a $2.5 / 15 \mathrm{~mm}^{-}$kazuchi $^{\mathrm{TM}}$ balloon (Kaneka Corporation, Kanagawa, Japan) was expanded up to a pressure of 6 atm and a Taxus ${ }^{\mathrm{TM}}$ (Boston Scientific, Galway, Ireland) $3.5 / 32 \mathrm{~mm}$ stent was implanted, leaving a residual stenosis of $10 \%$. For the LCX lesion, a 6-Fr Judkins left type 4 guide catheter was used, a 2.0/15 mm Ryujin ${ }^{\mathrm{TM}}$ balloon was expanded to a pressure of $6 \mathrm{~atm}$, leaving a residual stenosis of 70\%; an attempt was made to pass a Taxus ${ }^{\mathrm{TM}} 3.0 / 20 \mathrm{~mm}$ stent was rendered unsuccessful because of severe calcifications. The guide catheter was replaced with a 6-Fr Extra BackUp (EBU) 3.5 (Medtronic), but passage could not be performed. Resistance was perceived for the additional expansion during stent removal and it was observed that the stent was left at the lesion site (Fig. 1B). Residual stent removal was then unsuccessfully attempted with a small balloon. The guide catheter was replaced with an 8-Fr EBU 3.5 and unsuccessful attempts were made to remove the residual stent with the use of a Snare (Multi-snare Micro Set; Produkte fur die Medizin AG, Germany). Finally, the lost stent was compressed with a Xience V V ${ }^{\mathrm{TM}}$ (Abbott Vascular, Santa Clara, CA, USA). A 3.0/28 $\mathrm{mm}$ stent was transferred to the left main branch and removed using a Snare (Fig. 1C and D). Following the procedure, although the patient had persistent mild chest pain, no complications were apparent due to stent loss and the patient was discharged on medical treatment.

\section{Case 2}

A 57-year-old woman with a 5-year history of hypertension and diabetes under treatment presented to the emergency care center with a 3-day history of respiratory difficulty. An admission EKG showed a sinus rhythm and ST-segment depression in leads $\mathrm{V}_{4-6}$. On chest $\mathrm{X}$-ray, there were findings suggestive of pulmonary edema and cardiac enlargement. Echocardiography revealed overall decreased left ventricular mobility and the left ventricular ejection fraction which was decreased to $25 \%$. Percutaneous coronary angiography perform- 

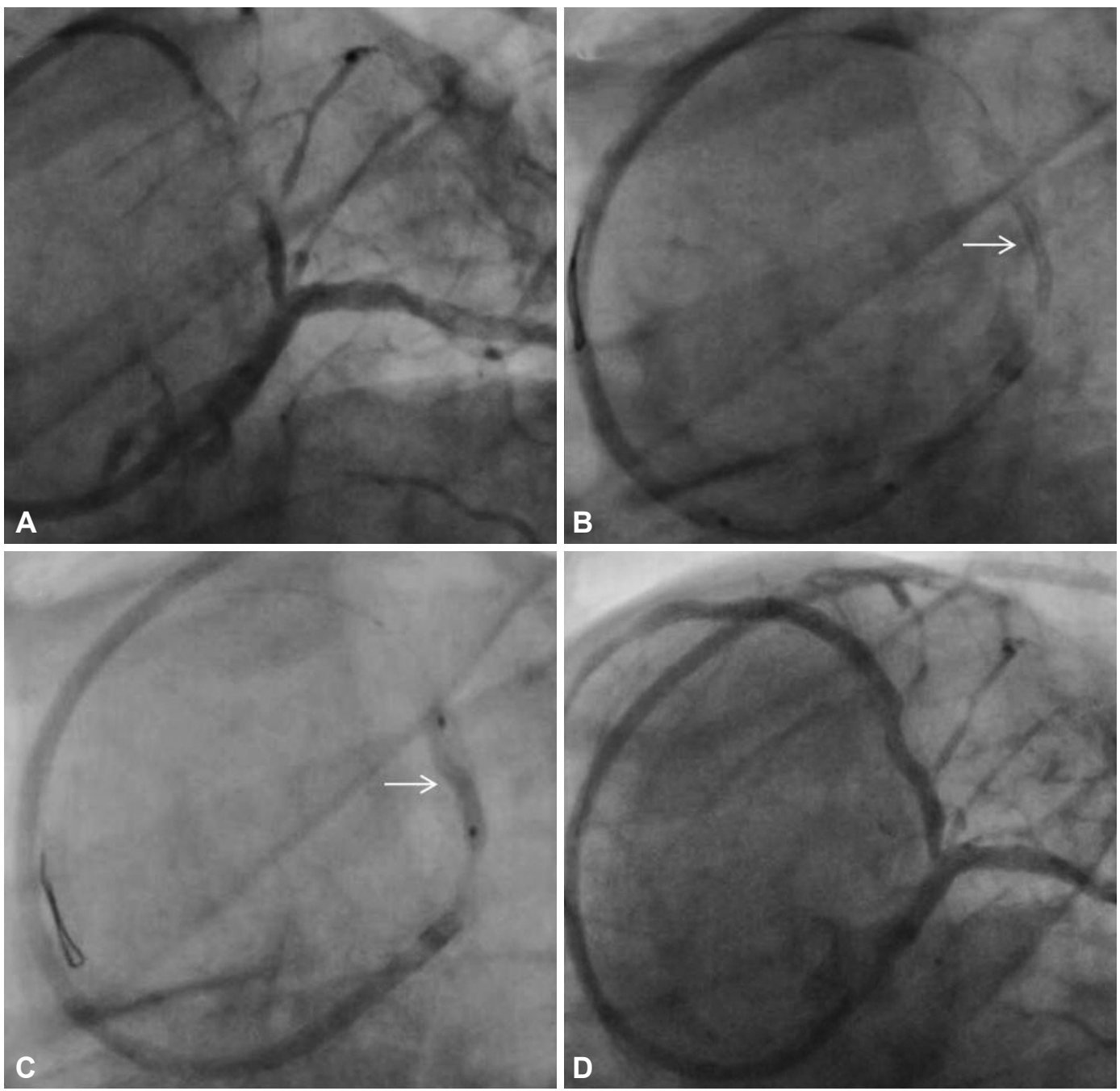

Fig. 2. Case 2. A: left coronary angiography showed severe, calcified stenosis of the proximal left anterior descending artery (LAD). B: the unexpanded lost stent $\left\{\right.$ Xience $\mathrm{V}^{\mathrm{TM}} 3.0 / 15 \mathrm{~mm}$ stent (arrow)\} is seen in the proximal LAD. C: the lost stent at the original site is depicted with an arrow; a 2.0/15 mm lkazuchi ${ }^{\mathrm{TM}}$ balloon was placed into the stent and dilatation was performed. D: the lost stent was successfully dilated with a residual $30 \%$ stenosis.

ed via the right femoral artery revealed $99 \%$ stenosis and calcifications in the proximal LAD, a normal LCX (Fig. 2A), and $50 \%$ stenosis in the mid-RCA. For the LAD lesion, a 6-Fr EBU 3.5 guide catheter was used to advance a guide wire and a 2.0/15 mm Ikazuchi ${ }^{\mathrm{TM}}$ balloon was dilated to a pressure of $8 \mathrm{~atm}$ after coronary artery dissection developed with acute obstructive findings. Passage of a Xience $\mathrm{V}^{\mathrm{TM}} 3.0 / 15 \mathrm{~mm}$ stent to the lesion was unsuccessfully attempted. A $2.5 / 15 \mathrm{~mm} \mathrm{Ka-}$ neka RX balloon ${ }^{\mathrm{TM}}$ (Kaneka Corporation) was then dilated to $12 \mathrm{~atm}$ and a subsequent attempt at stent passage resulted in leaving the stent in the proximal LAD lesion (Fig. 2B). To remove the lost stent, a guide wire was passed into the lost stent and removal was attempted without success with a small balloon. To fix the lost stent to the original site, a 2.0/15 mm Ikazuchi $^{\mathrm{TM}}$ balloon was placed into the stent and dilatation was performed to $14 \mathrm{~atm}$ (Fig. 2C). With progression of coronary artery detachment up to the mid-LAD portion, however, a thrombolysis in myocardial infarction (TIMI) flow grade 1 persisted. Again, using Xience $\mathrm{V}^{\mathrm{TM}}$ 2.5/18 mm and Xience $\mathrm{V}^{\mathrm{TM}}$ $2.5 / 23 \mathrm{~mm}$ stents, the stent was placed in the mid-portion lesions and dilatation was performed with a residual stenosis of approximately $30 \%$. The rate of blood flow was improved to TIMI 3, which finalized the procedure (Fig. 2D). The patient was discharged and then followed in an outpatient setting.

\section{Case 3}

A 79-year-old man with no history of hypertension, diabetes, smoking, or alcohol consumption was hospitalized because of a $>1$-month history of exertional chest pain. Sixteen years ago the patient had undergone thrombolytic therapy for an anterior and inferior wall myocardial infarction. Admission EKG showed sinus rhythm and Q waves in leads II, III, and $\mathrm{aV}_{\mathrm{F}}$, while echocardiography revealed no abnormal findings in the left ventricular ejection fraction or cardiac wall movement. Percutaneous coronary artery intervention was performed via the right femoral artery. Coronary angiogra- 

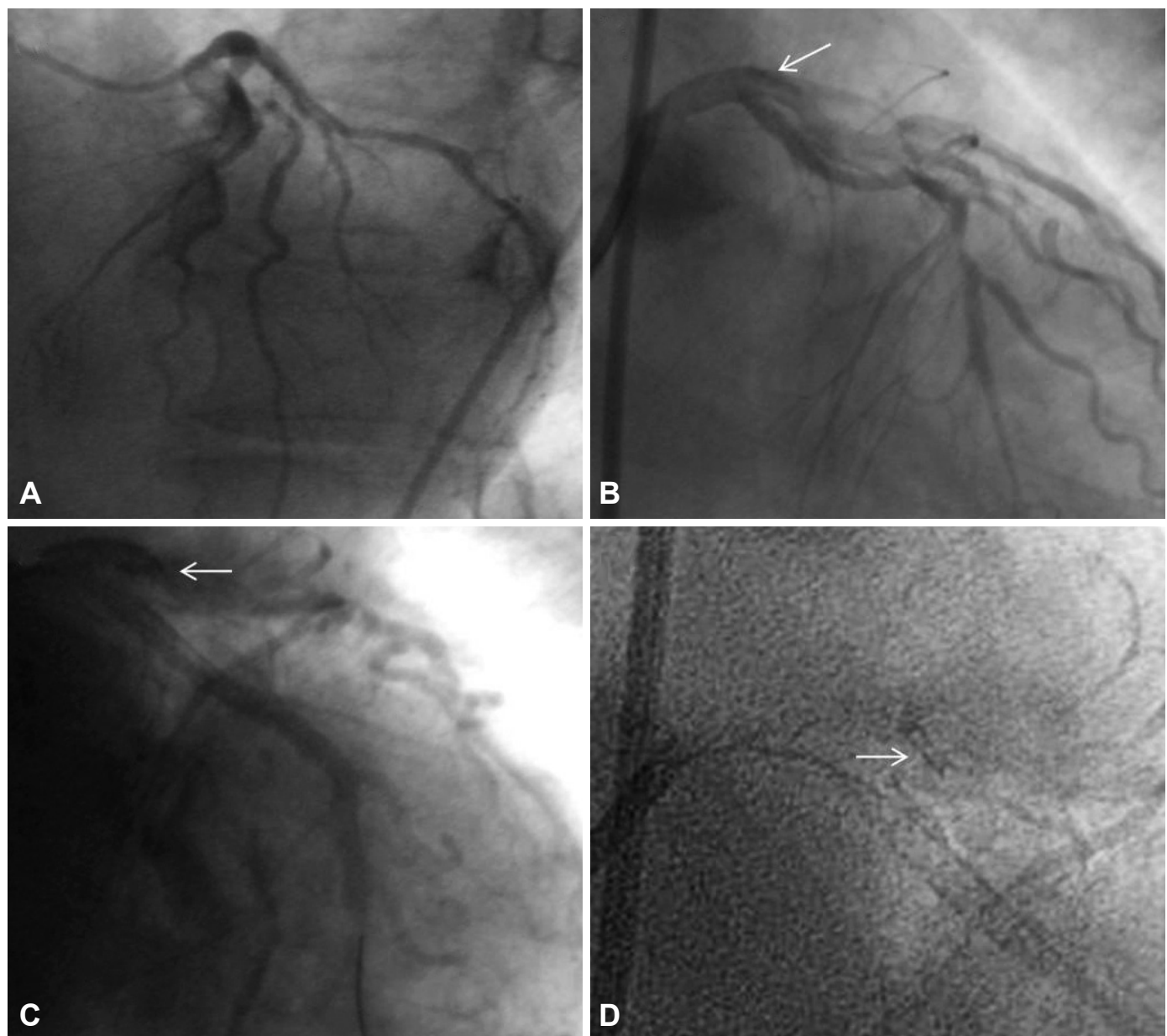

Fig. 3. Case 3 (Initial CAG). A: left coronary angiography showed chronic total occlusion of the mid-left anterior descending artery (LAD) and $70 \%$ stenosis proximally, and $90 \%$ stenosis of the distal left circumflex artery (LCX). B-D: the unexpanded lost stent (Endeavor ${ }^{\mathrm{TM}} 3.0 / 24 \mathrm{~mm}$ stent, arrow) is seen in the mid-LAD. C and D: the proximal-to-distal LCX underwent stenting with a PICO ${ }^{\mathrm{TM}} 3.0 / 24 \mathrm{~mm}$ stent and an Endeavor $^{\mathrm{TM}} 2.75 / 18 \mathrm{~mm}$ stent, respectively. CAG: coronary angiography.

phy revealed a complete mid-LAD obstruction, $70 \%$ stenosis in the proximal LCX, 90\% stenosis in the distal LCX (Fig. $3 \mathrm{~A}$ ), $40 \%$ stenosis in the proximal RCA, and $90 \%$ stenosis in the mid-RCA. A 6-Fr EBU guide catheter (Cordis Britetip, Miami, FL, USA) was used to advance the guide wire into the lesion, a 2.5/20 mm Ryujin ${ }^{\mathrm{TM}}$ balloon was dilated, and passage of a Pico ${ }^{\mathrm{TM}}$ stent (Amg Vacular, Bucharest, Romania) was attempted unsuccessfully. Again, a successful re-attempt was made with an Endeavor ${ }^{\mathrm{TM}}$ 3.0/24 mm stent (Medtronic Ireland, Galway, Ireland). For the LAD artery, a 6-Fr Judkins left type 4 guide catheter was passed, a 2.5/20 mm Ryujin $^{\text {TM }}$ balloon was dilated, and unsuccessful attempts were made with an Endeavor stent. After replacement with a 6-Fr EBU guide catheter, re-attempts at passage into the middle portion lesion resulted in stent retention because of severe resistance in the lesion (Fig. 3B). Because the lesion was already a complete obstruction, lack of stent removal was not deemed problematic and we proceeded with intervention of the proximal and distal LCX lesions, with insertion of a Pico ${ }^{\mathrm{TM}} 3.0 / 24$ $\mathrm{mm}$ stent and an Endeavor ${ }^{\mathrm{TM}}$ 2.75/18 mm stent, respectively (Fig. 3C and D). The patient completed the procedure in stable condition and was discharged.

One month later, the patient presented to the emergency care center with severe chest pain. The creatine kinase-MB fraction level was $149 \mathrm{ng} / \mathrm{mL}$ and the troponin T level was $2.4 \mathrm{ng} /$ $\mathrm{mL}$. An EKG showed new $\mathrm{Q}$ waves in leads $\mathrm{V}_{1-5}$ and echocardiography revealed a severe decrease in left ventricular anterior wall mobility. Percutaneous coronary artery intervention was performed emergently. There $\mathrm{wa}^{\circ}$ ). A 6-Fr guide catheter was used to pass a guide wire into the lesion and stent (Fig. 4B), a 3.0/15 mm Kaneka RX ${ }^{\mathrm{TM}}$ balloon was dilated to $6 \mathrm{~atm}$, and using an Endeavor ${ }^{\mathrm{TM}}$ 3.5/15 mm stent, the lost stent was compressed and inserted (Fig. 4C). Coronary angiography showed recovery of the hemodynamic profile (Fig. $4 \mathrm{D})$. The patient was discharged in stable condition and followed in an outpatient setting.

\section{Discussion}

In our series, the lost stent was removed using a loop snare in the first case, while in the second case, removal could not be done with the first method and dilatation was performed 

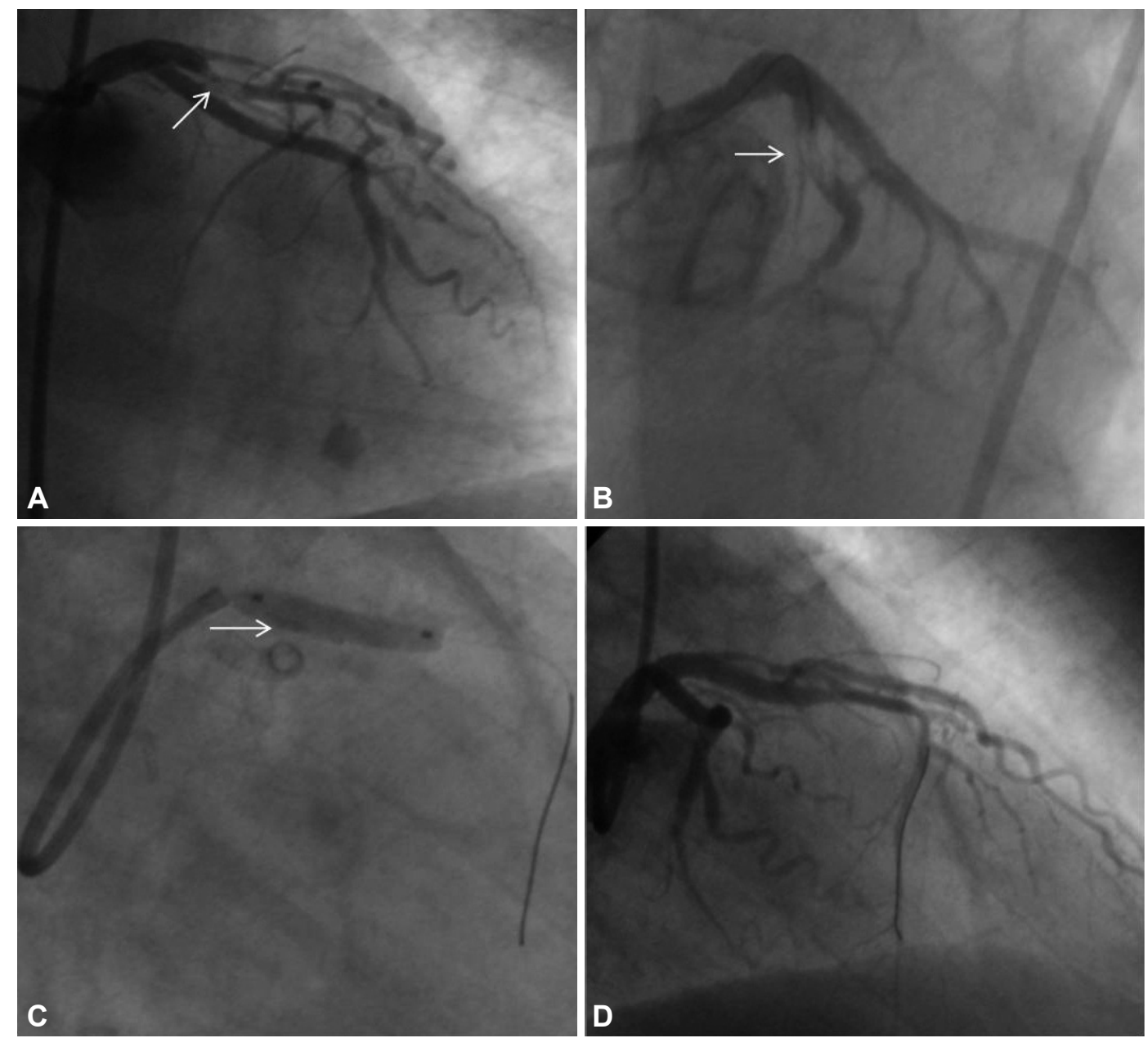

Fig. 4. Case 3 (Follow up CAG 1 month). A: a 90\% stenosis and the lost stent are apparent in the proximal LAD. B: a guide wire was passed into the lesion and stent. C: using a 3.0/15 mm Kaneka RX ${ }^{\mathrm{TM}}$ balloon dilatation was performed to 6 atm. Using an Endeavor ${ }^{\mathrm{TM}} 3.5 / 15 \mathrm{~mm}$ stent, the lost stent was compressed and then inserted. D: final Coronary angiography showed recovery of the hemodynamic profile. CAG: coronary angiography.

at the original site and fixed. In the third case, the lost stent was compressed and fixed.

Although the incidence of stent loss as a complication during percutaneous coronary artery intervention is relatively low, it may have dire consequences, including death. As illustrated by one of the cases reported, not removing the lost stent because it was in an area of chronic stenosis resulted in the occurrence of acute myocardial infarction requiring emergent re-intervention 1 month later.

A review of the literature revealed differences in the reported incidence rates; before 1999, the incidence of stent loss was $0.9-8.3 \%$, with a decrease to $<0.2 \%$ thereafter. Brilakis et al. ${ }^{5)}$ reported a $0.32 \%$ incidence of stent loss among 11,773 cases between 1994 and 2004. Stent loss pathophysiology includes cases in which lesion deflection or calcification is severe and the stent is captured within the lesion and only the balloon escapes (stent entrapment), the proximal part of the stent is damaged during insertion into the lesion and the stent is pulled during retraction within the guide catheter, and during the insertion of the stent into the lesion, the stent cannot pass and only the balloon passes (stent push-back).

All three cases of stent loss at our medical institution, as described in this report, were secondary to entrapment of the stent in the lesion. Risk factors for stent loss include severe lesion deflection, severe calcifications, severe vascular curvature, manual handling of the stent, direct insertion of the stent without balloon pre-dilatation of the lesion, and use of a smallsized stent. ${ }^{6-9}$ Because stent loss may result in stent embolism and myocardial infarction, it is recommended to remove the stent which by one of the following methods: 1) a small balloon is passed into the stent and dilated, then the stent is fixed and removed (small-balloon technique); 2) using two guide wires, a guide wire is passed into and out of the stent and the distal guide wire is then coiled and the stent is fixed (two-wire technique); and 3) a loop snare or various other instrument (forceps, cook fragment retriever, or basket) are used. ${ }^{10)}$

In cases in which the stent cannot be removed using the above methods, dilatation should be performed using a small balloon at the site of the stent loss, followed by dilatation with a larger size balloon and fixation. Also, there are methods 
in which the lost stent is compressed using another stent.

To help prevent stent loss is important to ensure a sufficient extent of dilatation in cases in which lesions are stenotic or deflection is severe, and to use a cutting balloon in those cases in which the first stent cannot be fully extended and there are severe calcifications. Special attention should also be paid to the collection of a stent and use of stents of smaller size should be avoided. ${ }^{11)}$

As described herein, stent loss occurring during interventional treatment can be successfully treated with non-surgical methods, and in cases in which the lost stent cannot be removed, the lost stent is fixed to the original site or compressed.

\section{REFERENCES}

1) Al Suwaidi J, Berger PB, Holmes DR Jr. Coronary artery stents. JAMA 2000;284:1828-36.

2) Park JG, Kim MH, Bae YJ, et al. Removal of dislodged stent by using $8 F r$ sheath and forceps during transradial coronary stenting. Korean Circ J 2000;30:1312-5.

3) Yang SS, Moon GH, Kim DH, et al. A case of a detached and entrapp- ed stent balloon catheter debris after coronary stenting. Korean Circ J 2001;31:584-7.

4) Eggebrecht $\mathrm{H}$, Haude M, von Birgelen $\mathrm{C}$, et al. Nonsurgical retrieval of embolized coronary stents. Catheter Cardiovasc Interv 2000;51: 432-40.

5) Brilakis ES, Best PJ, Elesber AA, et al. Incidence, retrieval methods, and outcomes of stent loss during percutaneous coronary intervention. Catheter Cardiovasc Interv 2005;66:333-40.

6) Lohavanichbutr K, Webb JG, Carere RG, et al. Mechanisms, management, and outcome of failure of delivery of coronary stents. Am J Cardiol 1999;83:779-81.

7) Laarman G, Muthusamy TS, Swart H, et al. Direct coronary stent implantation: safety, feasibility, and predictors of success of the strategy of direct coronary stent implantation. Catheter Cardiovasc Interv 2001;52:443-8.

8) Holmes DR Jr, Garratt KN, Popma J. Stent complications. J Invasive Cardiol 1998; 10:385-95.

9) Hoang V, Urban V, Chatelain P, et al. Randomized evaluation of 6 French Voda-type guiding catheters for left coronary artery angioplasty. Cathet Cardiovasc Diagn 1995;35:53-6.

10) Lee HY, Kim BH, Yoo WS, et al. Successful removal of a dislodged stent using a gooseneck snare. Korean J Med 2008;75(Suppl):S843-7.

11) Feldman T. Tricks for overcoming difficult stent delivery. Catheter Cardiovasc Interv 1999;48:285-6. 